\title{
Drug utilization patterns of antidepressants in Federal Neuro-Psychiatric Hospital Lagos, Nigeria
}

\author{
Oyinlade A. Kehinde*1, Emmanuel N. Anyika ${ }^{2}$, Isaac Abah ${ }^{3}$ \\ ${ }^{1}$ Federal Neuro-Psychiatric Hospital, Yaba, Lagos, Nigeria \\ ${ }^{2}$ Department of Clinical Pharmacy \& Biopharmacy, University of Lagos, Nigeria \\ ${ }^{3}$ Jos University Teaching Hospital, Jos, Plateau State, Nigeria
}

Received: June 12, 2017

DOI: $10.5430 /$ jha.v6n5p12
Accepted: August 15, 2017

URL: https://doi.org/10.5430/jha.v6n5p12

Online Published: August 23, 2017

\begin{abstract}
Backgroud: The paucity of information on prescribing patterns and use of antidepressants in accordance with practice guidelines necessitated this study in Nigeria.

Objective: To assess the prescribing patterns of antidepressants, average cost of prescriptions and the index of rational drug prescribing (IRDP) in a Nigerian tertiary care hospital.

Methods: A retrospective study which involved the assessment of 683 prescriptions and case records of patients who received antidepressants from $1^{\text {st }}$ January 2013 to $31^{\text {st }}$ December 2014 was conducted. Information on diagnosis, patients' demographics, prescribing patterns and cost of medications was obtained therefrom. Compliance to the World Health Organization (WHO) prescribing indicators and Nigerian Standard Treatment Guidelines (STG) was assessed. The IRDP for antdepressants was determined using a validated mathematical model. The statistical analysis was performed using SPSS version 20.

Results: Tricyclic antidepressants (TCAs) were the most commonly prescribed drug group (61.3\%), followed by selective serotonin re-uptake inhibitors (SSRIs) with a total of 38.7\%. On the average, three drugs were prescribed per prescription, while $60.3 \%$ and $38.3 \%$ of the drugs were prescribed from National Essential Medicine List (NEML) and STG respectively. The IRDP was 3.96 over 5 points. The average cost of drugs per prescription was 4.2 USD. The cost of drugs in the prescriptions written according to STG was lower compared to that in prescriptions not compliant with the STG $(p<.001)$.

Conclusions: TCAs are the most commonly prescribed antidepressants due to their affordability. The generic prescribing, medicines prescribed from the NEML and in compliance with the STG were less than the WHO standard. The rational drug use is suboptimal. Better prescribing habits, affordability and use of newer antidepressants should be encouraged by the hospital management.
\end{abstract}

Key Words: Drug utilization, Prescribing pattern, Antidepressants, Prescribing indicators, Treatment guideline

\section{INTRODUCTION}

People with mental health disorders such as depression have a mortality rate that is 2.22 times higher than those without mental disorders. Depression robs sufferers nearly a decade of life and accounts for 8 million deaths worldwide each year. ${ }^{[1]}$ Antidepressants are as effective as each other and are recommended as first-line treatment for the management of depression, with up to $60 \%$ response from patients within the first two weeks of treatment. ${ }^{[2]}$ Globally, antidepressants prescribing patterns have changed with tricyclic antidepressants (TCAs) and monoamine oxidase inhibitors (MAOIs) being gradually replaced by selective serotonin reuptake in-

*Correspondence: Oyinlade A. Kehinde; Email: oyincrowns@yahoo.com; Address: Federal Neuro-Psychiatric Hospital, Yaba, Lagos, Nigeria. 
hibitors (SSRIs) and novel antidepressants. ${ }^{[3]}$ Selecting the most suitable drug for the treatment of depression has clinical and economic implications since drug use, safety and cost of antidepressants vary among races. ${ }^{[4]}$ The National Institute for Health and Care Excellence (NICE) treatment guideline 2015 and other studies recommend generic SSRI as a first-choice drug for adults with depression and generalized anxiety disorder due to its favorable risk-benefit ratio. ${ }^{[5-7]}$ It was also found that fewer patients taking SSRI discontinued therapy compared to patients on TCAs that are prone to adverse effects. ${ }^{[8-10]}$ The most current Standard Treatment Guideline (STG) in Nigeria (2008) recommends TCAs and SSRIs for treatment of depression. ${ }^{[1]}$ Factors that affect the decision of mental health professionals' selection of antidepressants have been studied in various continents. Clinical experiences from developing countries differ from those of developed countries where non- pharmacological attributes like affordability and availability play a greater role in the prescription of drugs. ${ }^{[12]}$ In the US, the choice of antidepressants was associated mostly with the type of clinical symptoms and side-effects profile, ${ }^{[13]}$ while in Asia, psychiatrists considered demographic factors to be more important. ${ }^{[14]}$ In Europe, physician characteristics (age, specialization), patients' severity of depression, age, education and existence of comorbidity and economic issues were the determining factors. ${ }^{[15,16]}$

Drug utilization research is an eclectic collection of descriptive and analytical methods for the quantification, understanding, evaluation of the processes of prescribing, dispensing, consumption of medicines and the testing of interventions to enhance the quality of these processes. ${ }^{[17]}$ Information on patterns of existing and appropriate practice is an essential component for improving healthcare services in depressed patients. ${ }^{[18]}$

In Nigeria, data on antidepressant drugs utilization are limited. The following questions are therefore raised: What are the current drug utilization patterns in the health facility? Are the physicians using Essential Drugs List and Standard Treatment Guidelines (STG) for prescribing? Are the antidepressants affordable to the patients? The aim of the study was to evaluate the drug utilization patterns of antidepressants in the tertiary care hospital in Lagos.

\section{MATERIAls AND METHODS}

A two-year retrospective study of prescription patterns and drugs use was carried out using prescriptions generated from the out-patient clinic of the Federal Neuro-Psychiatric Hospital, Lagos, Nigeria ( $1^{\text {st }}$ January 2013 to $31^{\text {st }}$ December 2014). The study protocol was approved by the Institutional Ethics Committee of the hospital (FNPHY/ERC/15/122).
Patients whose prescriptions had any antidepressant medications regardless of the clinical indication or treatment format (monotherapy or in combination with other psychotherapeutic agents) were included in the study without repetition of the patients' prescriptions. The prescriptions were analyzed using WHO core drug indicators, ${ }^{[19]}$ STG and comparative cost of drugs. Collated data were analyzed using descriptive and inferential statistics. For the descriptive analysis, frequencies and proportions were reported while means at $95 \%$ confidence intervals were computed for continuous variables. The index of rational drug prescribing (IRDP) was determined by adapting a previously validated method derived from WHO prescribing indicators comprising five indices. Comparative costs of drugs were determined using box plot. Statistical analysis was performed using SPSS version 20.

\section{RESULTS}

A total of 683 prescriptions were analyzed. The association between patients' demographic characteristics and types of depression was evaluated.

Table 1 shows the distribution of different classes of depression and patients' demographic characteristics. A total of 224 patients $(32.8 \%)$ were males and 459 (67.2\%) were females, with male to female ratio approximately 1:2. In terms of gender, (male to female), the occurrence of bipolar depression is highest in the sampled prescriptions (52.7\% and $66.7 \%$ respectively), followed by moderate depression (22.8\% and $14.4 \%$ respectively), and severe depression (19.1\% and $12.4 \%$ respectively). Mild depression is the least occurring (5.4\% and $6.5 \%$ respectively).

Age distribution in ascending order shows that bipolar depression is the most prevalent among all the age groups (70.1\%: 61.4\%: 53.8\%: 50.8\%), followed by moderate depression (13.0\%: $17.2 \%$ : $25.5 \%$ : $18.0 \%$ ), and severe depression (13.9\%: 16.1\%: 16.0\%: 8.2\%). Mild depression is least prevalent (30\%: $5.3 \%$ : $4.7 \%: 23 \%)$. In the same order, marital status shows that bipolar depression is the most prevalent followed by moderate depression, then severe depression with mild depression as least prevalent. The Table also shows that married patients have more incidents of different forms of depression than single patients (and others). The prescription patterns for diagnosis of depression also follow the same trend for occupational status viz: bipolar $>$ moderate $>$ severe $>$ mild depression.

From the above data, the different types of depression are associated with the patients' gender at $p=.003$. Likewise the different types of depression were significantly associated with the age group $(p<.001)$. The different types of depres- 
sion were not significantly associated with marital status of sion are associated with the patients occupational status at the patients $(p=.075)$. Finally the different types of depres- $p=.005$.

Table 1. Association between diagnosis of depression and patients' demographic characteristics

\begin{tabular}{|c|c|c|c|c|c|c|}
\hline \multirow{2}{*}{ Variable } & Mild & Moderate & Severe & Bipolar & Total & \multirow{2}{*}{$p$-value } \\
\hline & Number (\%) & Number (\%) & Number $(\%)$ & Number (\%) & Number (\% of total) & \\
\hline \multicolumn{7}{|l|}{ Sex } \\
\hline - Male & $12(5.4)$ & $51(22.8)$ & $43(19.1)$ & $118(52.7)$ & $224(32.8)$ & .003 \\
\hline - Female & $30(6.5)$ & $66(14.4)$ & $57(12.4)$ & $306(66.7)$ & $459(67.2)$ & \\
\hline \multicolumn{7}{|l|}{ Age } \\
\hline - $15-30$ & $7(30)$ & $30(13.0)$ & $32(13.9)$ & $162(70.1)$ & $231(33.8)$ & $<.001$ \\
\hline - $31-45$ & $15(5.3)$ & $49(17.2)$ & $46(16.1)$ & $175(61.4)$ & $285(41.7)$ & \\
\hline - $46-60$ & $5(4.7)$ & $27(25.5)$ & $17(16.0)$ & $57(53.8)$ & $106(15.4)$ & \\
\hline - $61+$ & $14(23.0)$ & $11(18.0)$ & $5(8.2)$ & $31(50.8)$ & $61(8.9)$ & \\
\hline \multicolumn{7}{|l|}{ Marital status } \\
\hline - Single & $8(3.5)$ & $31(13.5)$ & $30(13.0)$ & $161(70.0)$ & $230(33.7)$ & .075 \\
\hline - Married & $28(7.2)$ & $70(18.0)$ & $63(16.2)$ & $228(58.6)$ & $389(57.0)$ & \\
\hline - Others & $5(7.8)$ & $16(25)$ & $7(10.9)$ & $36(56.3)$ & $64(9.3)$ & \\
\hline \multicolumn{7}{|l|}{ Occupation } \\
\hline - Government employed & $6(21.4)$ & $5(17.9)$ & $2(7.1)$ & $15(53.6)$ & $28(4.1)$ & .005 \\
\hline - Non-Government employed & $6(9.0)$ & $12(17.9)$ & $15(22.4)$ & $34(50.7)$ & $67(9.8)$ & \\
\hline - Self employed & $15(4.4)$ & $67(19.7)$ & $45(13.3)$ & $213(62.6)$ & $340(49.7)$ & \\
\hline - Retired & $3(8.8)$ & $9(26.5)$ & $5(14.7)$ & $17(50.0)$ & $34(5.0)$ & \\
\hline - Student & $3(3.0)$ & $13(12.9)$ & $13(12.9)$ & $72(71.3)$ & $101(14.8)$ & \\
\hline - Unemployed & $8(7.1)$ & $11(9.7)$ & $20(17.7)$ & $74(65.5)$ & $113(16.6)$ & \\
\hline
\end{tabular}

Table 2. Number of prescriptions of antidepressants by class and diagnosis

\begin{tabular}{lllllll}
\hline \multirow{2}{*}{ Name of drug/Class } & Prescriptions & \multicolumn{3}{l}{ Number of prescriptions per depression type } & \multirow{2}{*}{ \% of total prescriptions } \\
\cline { 3 - 6 } & $(\mathbf{N}=\mathbf{6 8 3})$ & Mild & Moderate & Severe & Bipolar & \\
\hline Amitryptiline (TCA) & 414 & 25 & 66 & 64 & 239 & $60.6 \%$ \\
Sertraline (SSRI) & 138 & 6 & 21 & 13 & 91 & $20.2 \%$ \\
Escitalopram (SSRI) & 80 & 4 & 17 & 12 & 47 & $11.7 \%$ \\
Fluoxetine (SSRI) & 28 & 1 & 6 & 3 & 18 & $4.1 \%$ \\
Paroxetine (SSRI) & 18 & 5 & 3 & 0 & 10 & $2.7 \%$ \\
Imipramine (TCA) & 3 & 0 & 1 & 0 & 2 & $0.4 \%$ \\
Clomipramine SR (TCA) & 2 & 0 & 0 & 2 & 0 & $0.3 \%$ \\
\hline
\end{tabular}

Note. TCA: Tricyclic antidepressants; SSRI: Selective serotonin reuptake inhibitors; SR: slow release

Table 2 shows the number of antidepressants prescribed by class and diagnosis. Tricyclic antidepressants constitute $61.3 \%$ of the antidepressants while selective serotonin reuptake inhibitors accounted for $38.7 \%$. Amitryptiline (TCA) and sertraline (SSRI) were the most frequently prescribed antidepressants (60.6\% and $20.2 \%$ respectively).

Table 3 shows the summary of the values of WHO prescribing indicators and Nigerian STG (2008) at 95\% confidence interval. Drug prescriptions from NEML, generic prescribing and STG were all below the WHO recommended value $(100 \%)$.
Table 4 shows the IRDP calculated using a mathematical model by Zhang and $\mathrm{Zhi}^{[20]}$ and adapted for the types of depression. It shows that injection safety and antibiotics prescription had the highest index of rational prescribing of 1 respectively. Index of polypharmacy was approximately 0.9 indicating rational prescribing to some extent. However, essential medicines index and generic prescribing were lower suggesting irrational prescribing. The overall IRDU was 3.96 over 5 points, indicating suboptimal rational prescribing in the treatment of depression in the study setting. The degrees of freedom $(\mathrm{F})$ and the $p$-values for the respective indices are also shown in the Table. 
Table 3. Summary of the values of WHO prescribing indicators and Nigerian Standard Treatment Guideline at 95\% CI

\begin{tabular}{ll}
\hline Indicator & Value (95\% CI) \\
\hline \% Drugs prescribed from NEML & $60.3(57.7-62.8)$ \\
$\%$ Drugs prescribed by generic name & $56.9(54.5-59.2)$ \\
$\%$ Prescriptions including an injection & $4.0(3.3-4.9)$ \\
$\%$ Prescriptions including antibiotics & $0.2(0.0-0.4)$ \\
Mean $( \pm S D)$ number of prescribed drugs per prescription & $3.2 \pm 1.4$ \\
$\%$ of drugs prescribed according to STG & $38.3(34.7-41.9)$ \\
\hline
\end{tabular}

Note. CI, confidence interval; SD, standard deviation; NEML, National Essential Medicines list; STG, Standard Treatment Guideline

Table 4. IRDP* according to types of depression

\begin{tabular}{|c|c|c|c|c|c|c|}
\hline $\begin{array}{l}\text { Type of } \\
\text { depression }\end{array}$ & $\begin{array}{l}\text { Essential } \\
\text { medicine index }\end{array}$ & $\begin{array}{l}\text { Generic prescribing } \\
\text { index }\end{array}$ & $\begin{array}{l}\text { Index of safety of } \\
\text { injection }\end{array}$ & $\begin{array}{l}\text { Index of rational } \\
\text { antibiotics prescribing }\end{array}$ & $\begin{array}{l}\text { Index of } \\
\text { polypharmacy }\end{array}$ & IRDU \\
\hline Mild & $\begin{array}{l}0.61 \\
(0.48-0.74)\end{array}$ & $\begin{array}{l}0.47 \\
(0.34-0.59)\end{array}$ & $\begin{array}{l}1 \\
(1.0-1.0)\end{array}$ & $\begin{array}{l}1 \\
(1.00-1.00)\end{array}$ & $\begin{array}{l}0.95 \\
(0.91-0.98)\end{array}$ & $\begin{array}{l}4.03 \\
(3.82-4.24)\end{array}$ \\
\hline Moderate & $\begin{array}{l}0.6 \\
(0.53-0.67)\end{array}$ & $\begin{array}{l}0.47 \\
(0.40-0.53)\end{array}$ & $\begin{array}{l}1 \\
(1.00-1.00)\end{array}$ & $\begin{array}{l}1 \\
(1.00-1.00)\end{array}$ & $\begin{array}{l}0.97 \\
(0.95-0.99)\end{array}$ & $\begin{array}{l}4.04 \\
(3.92-4.16)\end{array}$ \\
\hline Severe & $\begin{array}{l}0.67 \\
(0.61-0.74)\end{array}$ & $\begin{array}{l}0.61 \\
(0.54-0.67)\end{array}$ & $\begin{array}{l}0.98 \\
(0.95-1.00)\end{array}$ & $\begin{array}{l}1 \\
(1.00-1.00)\end{array}$ & $\begin{array}{l}0.96 \\
(0.94-0.98)\end{array}$ & $\begin{array}{l}4.23 \\
(4.10-4.34)\end{array}$ \\
\hline Bipolar & $\begin{array}{l}0.59 \\
(0.56-0.61)\end{array}$ & $\begin{array}{l}0.6 \\
(0.57-0.62)\end{array}$ & $\begin{array}{l}0.86 \\
(0.83-0.89)\end{array}$ & $\begin{array}{l}1 \\
(1.00-1.00)\end{array}$ & $\begin{array}{l}0.82 \\
(0.80-0.84)\end{array}$ & $\begin{array}{l}3.87 \\
(3.81-3.92)\end{array}$ \\
\hline Total & $\begin{array}{l}0.6 \\
(0.58-0.63)\end{array}$ & $\begin{array}{l}0.57 \\
(0.55-0.59)\end{array}$ & $\begin{array}{l}1 \\
(1.00-1.00)\end{array}$ & $\begin{array}{l}1 \\
(1.00-1.00)\end{array}$ & $\begin{array}{l}0.88 \\
(0.86-0.89)\end{array}$ & $\begin{array}{l}3.96 \\
(3.91-4.01)\end{array}$ \\
\hline $\mathrm{F}$ & 1.99 & 6.773 & 21.165 & 0.597 & 38.166 & 10.696 \\
\hline$p$-value & .114 & .000 & .000 & .617 & .000 & .000 \\
\hline
\end{tabular}

Note. ${ }^{*}$ The closer to 1 , the more rational the drug prescribed

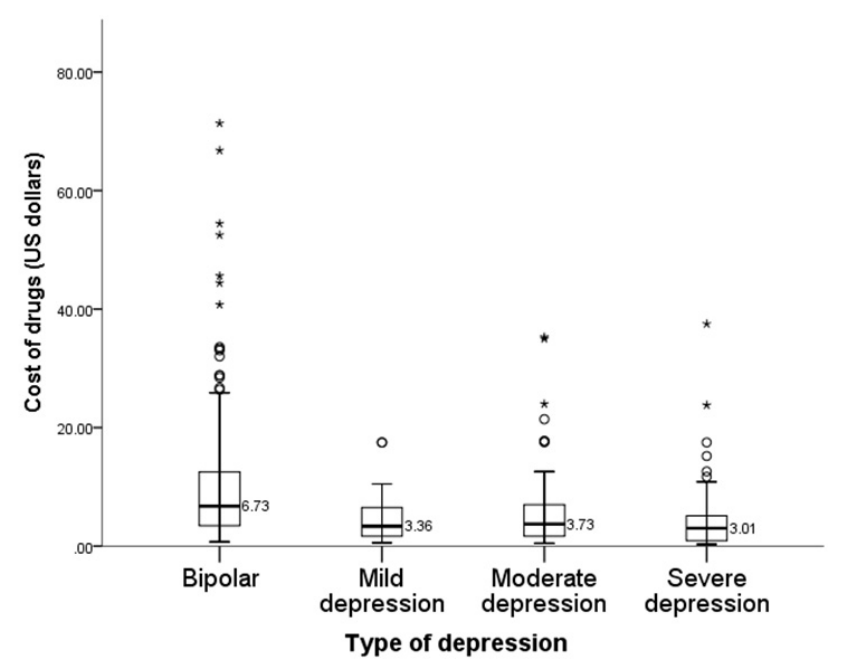

Figure 1. Comparative cost of drugs for treating different types of depression

Figure 1 shows the comparative cost of drugs for treating the different types of depression in dollars (USD). The average cost of drugs per prescription in dollar was 4.2 USD (95\% confidence interval at an exchange rate of 200 Naira per dollar during the period of research). The cost of drugs for treating different types of depression was significantly different between the different types of depressions Published by Sciedu Press $(p<.001)$.

Figure 2 shows the comparative cost of drugs based on compliance with STG in dollars (USD) using the box plot. The cost of drugs (per prescription) written according to the standard treatment guideline (4.13 USD) was less than the cost of drugs (per prescription) not compliant with the guideline (7.95 USD).

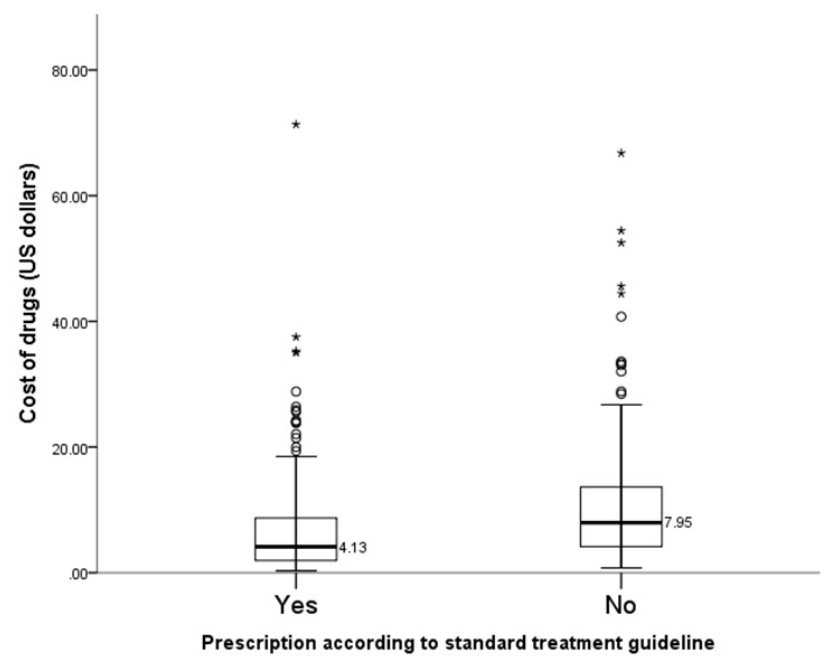

Figure 2. Comparative cost of drugs based on compliance with Standard Treatment Guideline 


\section{DiscuSsion}

Findings from this study reflect the prescription patterns of antidepressant medicines in the health care facility. Demographic details show that depression significantly affects the economically productive age group of 31-45 years by as high as $42 \%$, and the self employed group (49.7\%). This might be due to work related stress and socioeconomic factors. Gender distribution shows that the occurrence of depression is more in females $(67.2 \%)$ than in males. This is similar to the findings of other researchers. ${ }^{[3,21,22]}$ This occurrence is hypothesized to be due to hormonal influence, the effect of child birth and different psychosocial stress among women. ${ }^{[23]}$

Contrary to the view that SSRIs are preferred over older classes of antidepressants owing to less severe adverse effects, TCAs accounted for $61.3 \%$ of antidepressants used in the hospital under study; with SSRIs as only $(38.7 \%)$. This is consistent with the prescribing patterns of other studies carried out in Nigeria. ${ }^{[24,25]}$ This could be attributed to the affordability of TCAs compared to SSRIs. Various practice guidelines for depressive disorders uniformly recommend generic formulations of SSRIs ${ }^{[26-28]}$ as first line treatment This could be due to its better side effects profile, wider therapeutic window, once daily dose frequency, and less dose titration, which are expected to improve patients' adherence. ${ }^{[29,30]}$ It is necessary to consider the use of more cost effective generic SSRIs than the more expensive ones currently available in the study setting. This would enhance rational prescribing and affordability. In contrast to the findings of this study, SSRIs were the most frequently prescribed drugs in studies carried out in Asia, Europe, North America and India ${ }^{[3,14,15,21,31-34]}$ with decreased use of TCAs. Factors such as differences in culture, practice, promotional activity ${ }^{[32,35,36]}$ and national income ${ }^{[37]}$ contribute to these regional differences.

WHO recommended reference value for the average number of medicines prescribed is less than 2 per patient. ${ }^{[38,39]}$ Our findings show a higher number of medicines prescribed (3) per patient encounter than those reported by the WHO fact book for the African region (2.6), Europe (2.5), Southeast Asia (2.5) and the Americas (1.8). ${ }^{[39]}$ The use of more than one medicine is a common practice in psychiatry. ${ }^{[40,41]} \mathrm{A}$ possible rationale for antidepressants polypharmacy is that one of the agents is being utilized for antidepressant effects while the second is targeting co-morbid conditions such as insomnia or agitation. Another justification is that a number of African countries are experiencing a double disease burden of both communicable and non-communicable diseases. ${ }^{[22]}$ Increased risk of adverse drug effects as a result of polypharmacy could create a cycle of health demands and costs as new treatments may be required. ${ }^{[43]}$ In a study by
Uzochukwu et al., ${ }^{[4]}$ the percentage of patients remembering their dosing schedules decreased significantly as the number of medicines increased. Also, there was a direct correlation between the number of medicines prescribed and the occurrence of adverse events in South Africa. ${ }^{[45]}$ Avoidance of polypharmacy in the management of depression is necessary to reduce the disease burden and health cost to the patients.

The generic prescribing rate in this study (57\%) was lower than the recommended WHO value of $100 \%$, WHO fact book for the African region (60\%) and Western Pacific region $(78 \%)$. The rate was higher than that of Eastern Mediterranean $(27.7 \%)$ and Southeast Asian regions (48.9\%). ${ }^{[39]}$ Over 45 top brand medications including antidepressants are expected to have their patent expire between 2011 and 2020 . ${ }^{[46]}$ The expiration of the innovator brand patents will improve availability/accessibility of antidepressants. The reduced cost of these medicines could become an incentive that would drive generic prescribing of antidepressants. Furthermore, studies aimed at demonstrating the significance or otherwise of different outcomes between originators and generic antidepressants should be carried out. The outcomes would contribute to increased generic prescribing ${ }^{[47-50]}$ and subsequent reduction in treatment costs and prescriptions of innovator medicines. This is important for resource-poor countries like Nigeria.

The percentages of encounters with antibiotics $(0.2 \%)$ and injections $(4.0 \%)$ per patient were less than the WHO recommended prescribing indicator values of $30 \%$ and $20 \%$ respectively. The low value for antibiotics may be due to the fact that the health institution is a psychiatric hospital and most non-psychiatric cases are referred to teaching hospitals.

Drugs prescribed (60\%) from the National Essential Medicines list (NEML) were lower than the recommended WHO optimal value of $100 \%$. The NEML prescribing rate is lower when compared to estimates reported for other regions like the Americas (71.4\%) and South East Asia (81\%). ${ }^{[51]}$ Similar studies revealed $100 \%, 99.2 \%, 70.6 \%$ and $100 \%$ conformance to NEML respectively. ${ }^{[10,16-18]}$ The non-optimal use of NEML could be attributed to various factors such as unavailability or ineffective distribution of the list, nonsensitization among health workers and a general lack of enforcement mechanisms. ${ }^{[52-54]}$ Other studies have revealed that the main source of information for prescribers were the medical representatives ${ }^{[53,55]}$ who may over-represent the efficacy of medicines, discredit the efficacy of competitor brands and likely to induce prescribers to prescribe outside established guidelines. ${ }^{[56,57]}$

A mathematical model invented by Zhang and Zhi was adapted to assess rational drug use comprehensively and 
also determine the IRDP. ${ }^{[20]}$ The indices of rational drug use show that injection safety and antibiotics prescribing had the highest index of rational prescribing of 1 respectively. Index of polypharmacy was approximately 0.9 , which is close to the optimal level of 1 . However, essential medicine index (0.60) and generic prescribing (0.57) were lower; suggesting that the generic name and National essential medicines list were not widely used in the health facility. The overall IRDP was about 4 out of 5 points, indicating a close but not optimal rational prescribing in the treatment of depression in this study setting. In contrast, the overall IRDPs were 3.32\%[58] and $2.71 \%,{ }^{[59]}$ in other studies.

The average cost per prescription of antidepressants was 4.2 USD. The cost of treatment was highest and most variable in bipolar depression at an average cost of 7 USD with the greatest variability in the cost of medications. Surprisingly, the median cost of medicines for treatment of severe depression was less than those for mild and moderate depression. The comparative cost of antidepressants based on compliance with STG showed that prescriptions with STG had lower cost than the alternatives (non-compliance). Educating healthcare workers, implementing enabling policies, and enforcement of the use of STG would help to ameliorate the patients' healthcare needs.

Affordability of drugs is an important factor in a developing country like Nigeria. Physicians should prescribe drugs to suit the economic capability of the patients that usually purchase their medications through the user fees. Patients usually procure antidepressants from the hospital because they are cheaper compared to the prices in retail pharmacies around. In addition, the hospital is the only specialized psychiatric hospital in Lagos where such medications are often available. The newer antidepressants such as serotoninnorepinephrine reuptake inhibitors (SNRIs) are not available in the study setting. The high cost of these medications could also be responsible for their unavailability. Medical aid insurance scheme would be of great benefit to depressed patients in a resource limited country like Nigeria. The role of government and other stakeholders would ameliorate the burden on depressed patients.

\section{STRENGTHS AND LIMITATIONS}

\subsection{Strengths}

This study provides important and useful information on prescribing pattern of antidepressants in a Nigerian setting. The IRDP used in this study revealed an extensive rational drug prescribing. Important information on patterns of existing practice and compliance to STG was ascertained. Furthermore, cost implications as regards the compliance with STG were identified.

\subsection{Limitations}

The study was a retrospective one with limitations such as incomplete or missing clinical data that could have been obtained with prospective study. The study is also limited to one neuro-psychiatric hospital, thereby limiting its generalization. Extending the study to other neuro-psychiatric hospitals in Nigeria would enhance the generalizability of the findings.

\section{Conclusions}

Our study showed that older antidepressants were still largely prescribed despite advocacy for newer ones. The overall IRDP was not optimal but could still be improved upon. Generic prescribing and the use of Essential Medicines List should be encouraged. Collaborative efforts from all stakeholders are necessary to promote rational drug prescribing. Copies of practice guidelines should be made available to healthcare professionals in the hospital. In addition, regular educational training and procurement of more cost effective generic antidepressants are needed to enhance rational drug use, ensure optimal utilization of antidepressants and also improve patients' health outcomes.

\section{ACKNOWLedgements}

The authors are grateful to the staff of the medical record and pharmacy department of the hospital for their contribution to the successful completion of the study.

\section{Conflicts of InTEREST Disclosure}

The authors declare they have no conflict of interest.

\section{REFERENCES}

[1] Walker ER, McGee RE, Druss BG. Mortality in Mental Disorders and Global Disease Burden Implications. JAMA Psychiatry. 2015; 72(4): 334. PMid: 25671328. https ://doi.org/10.1001/jama psychiatry.2014.2502

[2] Posternak MA, Zimmerman M. Is there a delay in the antidepressant effect? A meta-analysis. Journal of Clinical Psychiatry. 2005.
[3] Lahon K, Shetty HM, Paramel A, et al. A Retrospective Drug Utilization Study of Antidepressants in the Psychiatric Unit of a Tertiary Care Hospital. Journal of Clinical and Diagnostic Research. 2011; 5: 1069-1075. Available from: http://www.jcdr.net/article s/PDF/1521/39-\%202864.pdf

[4] Weilburg JB, Stafford RS, O'Leary KM, et al. Costs of antidepressant medications associated with inadequate treatment. American Journal 
of Managed Care. 2004; 10(6): 357-365. PMid: 15209479. Available from: https://www.ncbi.nlm.nih.gov/pubmed/15209479

[5] The National Institute for Health and Care Excellence. The NICE Guideline on the Treatment and Depression the Treatment and Management of Depression. NICE guidelines [CG90]. 2009; 1-592. Available from: http://www.ncbi.nlm.nih.gov/books/NBK55 364/

[6] Gartlehner G, Hansen RA, Morgan LC, et al. Comparative benefits and harms of second-generation antidepressants for treating major depressive disorder: An updated meta-analysis. Annals of Internal Medicine. 2011.

[7] Ferguson JM. SSRI Antidepressant Medications: Adverse Effects and Tolerability. Primary Care Companion to the Journal of Clinical Psychiatry. 2001; 3(1): 22-27. PMid: 15014625. https://doi.or g/10.4088/PCC.v03n0105

[8] Anderson IM. SSRIS versus tricyclic antidepressants in depressed inpatients: a meta-analysis of efficacy and tolerability. Depression and Anxiety. 1998; 7(Suppl 1): 11-7. https://doi .org/10.100 2/(SICI) 1520-6394(1998) $7: 1+<11::$ AID-DA4>3.0.CO;2-I

[9] Edwards JG, Anderson I. Systematic review and guide to selection of selective serotonin reuptake inhibitors. Drugs. 1999; 57(4): $507-$ 33. PMid: 10235690. https ://doi.org/10.2165/00003495-1 99957040-00005

[10] Federal Ministry of Health. Standard Treatment Guidelines, 1st Edition. Nigeria; 2008. Available from: https://localhost/Us ers/keithhenry/Documents/Papers/1999/Feighner/TheJ ournalof clinicalpsychiatry1999Feighner.pdf

[11] Federal Ministry of Health. Standard Treatment Guidelines, 1st Edition. Nigeria; 2008. Available from: https ://www . neuroaro.com/index.php/resources/... /21-standard-treatment-guidelines

[12] Rahman R, Siddiqi N, Ansari M, et al. Factors influencing the selection of antidepressants by Pakistani psychiatrics. European Psychiatry. 2013; 28: 1. https://doi.org/10.1016/S0924-9338(13) 773 49-8

[13] Zimmerman M, Posternak M, Friedman M, et al. Which factors influence psychiatrists' selection of antidepressants? American Journal of Psychiatry. 2004; 161(7): 1285-1289. PMid: 15229063. https://doi.org/10.1176/appi.ajp.161.7.1285

[14] Sim K, Lee NB, Chua HC, et al. Newer antidepressant drug use in East Asian psychiatric treatment settings: REAP (Research on East Asia Psychotropic Prescriptions) study. British Journal of Clinical Pharmacology. 2007; 63(4): 431-437. PMid: 17076698. https://doi.org/10.1111/j.1365-2125.2006.02780.x

[15] Bauer M, Monz BU, Montejo AL, et al. Prescribing patterns of antidepressants in Europe: Results from the Factors Influencing Depression Endpoints Research (FINDER) study. European Psychiatry. 2008; 23(1): 66-73. PMid: 18164600. https://doi.org/10.1016/j . eurpsy.2007.11.001

[16] Maric NP, Stojiljkovic DJ, Pavlovic Z, et al. Factors influencing the choice of antidepressants: A study of antidepressant prescribing practice at University Psychiatric Clinic in Belgrade. Vojnosanitetski Pregled. 2012; 69(4): 308-313.

[17] Chamoli H, Mathur P, Kothiyal P. Drug utilization pattern and effectiveness analysis in diabetes mellitus at a tertiary care centre in Dheradun. International Journal of Universal Pharmacy and Bio Science. $2013 ; 2(6)$ : 265-275. Available from: http://ijupbs .com /Uploads/18.\%20RPA131400248014.pdf

[18] Goyal V, Munjal S, Gupta R. Drug utilization pattern of psychotropic drugs prescribed in the psychiatric department of a tertiary care government hospital, Rajasthan. Journal of Dental and Medical Sciences.
2016; 15(7): 80-87.https://doi.org/10.9790/0853-1507780 87

[19] World Health Organization. How to Investigate Drug Use in Health Facilities: Selected Drug Use Indicators. WHO/DAP/93.1. World Health Organization, Geneva. 1993; 1-87. Available from: http: //apps . who.int/medicinedocs/en/d/Js2289e/

[20] Zhang Y, Zhi M. Index system, appraising method for comprehensive appraisal. Journal of North Jiaotong Univ. 1995; 19: 393-400. Available from: http://en.cnki.com.cn/Article_en/CJFDTO TAL-BF JT503.023.htm

[21] Soh TH, Lim L, Chan HN, et al. Antidepressant Prescribing Patterns for Depressive and Anxiety Disorders in a Singapore Hospital. Open Journal of Psychiatry. 2015; 5(02): 144152. https: //doi.org/10.4236/ojpsych.2015.52016

[22] Abubakar K, Muhammad A, Jimoh A, et al. Prescription Pattern of Antipsychotic Drugs - A Case study of Neuropsychiatric Hospital in North-western Nigeria. European Journal of Scientific Research. 2013; 95: 332-337. Available from: http://www . academia.edu/21089210/Prescription_Pat tern_of_Antipsychotic_Drugs-A_Case_study_of_a_Neu ro-psychiatric_Hospital_in_North-Western_Nigeria

[23] Piparva K, Singh A, Trivedi H, et al. Drug utilization study of psychotropic drugs in outdoor patients in a teaching hospital. Indian Journal of Psychological Medicine. 2011; 33(1): 54. PMid: 22021954. https://doi .org/10.4103/0253-7176.85396

[24] Ezenduka C, Ubochi V, Ogbonna B. The Utilization Pattern and Costs Analysis of Psychotropic Drugs at a Neuropsychiatric Hospital in Nigeria. British Journal of Pharmaceutical Research. 2014; 4(3): 325-337. https://doi .org/10.9734/BJPR/2014/5988

[25] Arute J, Onwusah D, Wilson M, et al. Pattern of prescription of Psychotropic medications in Psychiatric Hospital Uselu, Benin city, Nigeria. World Journal of Pharmaceutical Research. 2015; 4(10): 2253-2256. Available from: www.wjpr.net/download/article/ 1444043895.pdf

[26] Kennedy SH, Lam RW, Cohen NL, et al. Clinical guidelines for the treatment of depressive disorders. IV. Medications and other biological treatments. Canadian Journal of Psychiatry. 2001; 46(1): 138S-58S.

[27] NICE. Depression in adults with a chronic physical health problem. The NICE guideline on treatment and management. Depression. 2010. Available from: http://guidance.nice.org.uk/CG91/QuickR efGuide/pdf/English

[28] Cipriani A, Barbui C, Butler R, et al. Depression in adults: drug and physical treatments. Clin Evid. 2011; 20: 1-40. Available from: ht tp://www. pubmedcentral.nih.gov/articlerender.fcgi?

[29] Rickels K, Schweizer E. Clinical overview of serotonin reuptake inhibitors. Journal of Clinical Psychiatry. 1990; 51: 9-12. Available from: http://journals.sagepub.com/doi/abs/10.11 $77 / 106002809402801207$

[30] Peretti S, Judge R, Hindmarch I. Safety and tolerability considerations: tricyclic antidepressants vs. selective serotonin reuptake inhibitors. Acta Psychiatr Scand Suppl. 2000; 403: 17-25. PMid: 11019931. https://doi.org/10.1111/j.1600-0447.2000.t b10944.x

[31] Avanthi E, Somashekar H, Kumar L, et al. Prescribing pattern of antidepressants in psychiatric unit of a tertiary care hospital. International Journal of Basic \& Clinical Pharmacology. 2014; 3(4): 6 https : //doi.org/10.5455/2319-2003.ijbcp20140820

[32] Muhammad M, Kyle W. International variation in drug utilization: Antidepressants utilization in North America, Greece, and Ireland. Journal of Health Specialties. 2013; 1(2): 78-83. https : //doi.org/10.4103/1658-600X.114689 
[33] Chee KY, Tripathi A, Avasthi A, et al. International study on antidepressant prescription pattern at 40 major psychiatric institutions and hospitals in Asia: A 10-year comparison study. AsiaPacific Psychiatry. 2015; 7(4): 366-374. PMid: 25706498. https : //doi.org/10.1111/appy. 12176

[34] Abbing-Karahagopian V, Huerta C, Souverein PC, et al. Antidepressant prescribing in five European countries: Application of common definitions to assess the prevalence, clinical observations, and methodological implications. European Journal of Clinical Pharmacology. 2014; 70(7): 849-857. PMid: 24793010. https://doi.org/10.1 007/s00228-014-1676-z

[35] Zito JM, Safer DJ, Berg L, et al. A three-country comparison of psychotropic medication prevalence in youth. Child and Adolescent Psychiatry and Mental Health. 2008; 2(1): 26. PMid: 18817536. https://doi.org/10.1186/1753-2000-2-26

[36] Fisch HU, Gillis JS, Daguet R. A cross-national study of drug treatment decisions in psychiatry. Med Decis Making. 1982; 2(2): 167. PMid: 7167045. https : //doi .org/10.1177/0272989X820020 0209

[37] Hoebert JM, Mantel-Teeuwisse AK, van Dijk L, et al. Do rheumatoid arthritis patients have equal access to treatment with new medicines?: tumour necrosis factor-alpha inhibitors use in four European countries. Health Policy. 2012; 104(1): 76-83. PMid: 22079753. https://doi.org/10.1016/j.healthpol.2011.10.011

[38] Isah A, Laing R, Quick J, et al. The Development of Reference Values for the WHO Health Facility Core Prescribing Indicators. West African Journal of Pharmacology and Drug Research. 2001; 18(1): 6-11. https://doi.org/10.4314/wajpdr.v18i1.14718

[39] Harvard Medical School and Harvard Pilgrim Health. World Health Organization. Using indicators to measure country pharmaceutical situations Fact Book on WHO Level I and Level II monitoring indicators, edn. Geneva: World Health Organization; 2006. Available from: http://apps. who.int/medicinedocs/documents/ s14101e/s14101e

[40] Famuyiwa OO. Psychotropic Polypharmacy in Nigeria. The danger can be avoided and cost reduced. Tropical Doctor. 1983; 18(1): 7-11. PMid: 3341093. https ://doi.org/10.1177/00494755880180 0103

[41] Adamson TA. Prescribing habits for psychiatric in-patient admissions in a Nigerian psychiatric hospital. African Journal of Medicine and Medical Sciences. 1995; 24(3): 261-267. PMid: 8798962. Available from: http://www. embase.com/search/results?su baction=viewrecord\&f rom=export\&id=L126271772

[42] de-Graft Aikins A, Unwin N, Agyemang C, et al. Tackling Africa's chronic disease burden: from the local to the global. Globalization and Health. 2010; 6(1): 5. PMid: 20403167. https://doi.org/ 10.1186/1744-8603-6-5

[43] Patterson SM, Cadogan CA, Kerse N, et al. Interventions to improve the appropriate use of polypharmacy for older people. The Cochrane Database of Systematic Reviews. 2014; 10. https ://doi .org/10 .1002/14651858. CD008165.pub3

[44] Uzochukwu BS, Onwujekwe OE, Akpala CO. Effect of the BamakoInitiative drug revolving fund on availability and rational use of essential drugs in primary health care facilities in south-east Nigeria. Health Policy and Planning. 2002; 17(4): 378-383. PMid: 12424209. https://doi.org/10.1093/heapol/17.4.378
[45] Kapp PAA, Klop ACC, Jenkins LSS. Drug interactions in primary health care in the George subdistrict, South Africa: A crosssectional study. South African Family Practice. 2013; 55(1): 78-84. https://doi.org/10.1080/20786204.2013.10874307

[46] Schacht W. Drug patent expirations: potential effects on pharmaceutical innovation. Congressional Research Service. 2012. Available from: https://ipmall.law.unh.edu/sites/default/files /hosted_resources/crs/R42399_120302.pdf

[47] Kesselheim AS. Clinical Equivalence of Generic and Brand-Name Drugs Used in Cardiovascular Disease. JAMA. 2008; 300(21): 2514. PMid: 19050195. https://doi.org/10.1001/jama. 2008.758

[48] Gagne JJ, Choudhry NK, Kesselheim AS, et al. Comparative effectiveness of generic and brand-name statins on patient outcomes: A cohort study. Annals of Internal Medicine. 2014; 161(6): 400-407. PMid: 25222387. https://doi.org/10.7326/M13-2942

[49] Veronin MA. Should we have concerns with generic versus brand antimicrobial drugs? A review of issues. Journal of Pharmaceutical Health Services Research. 2011.

[50] Paton C. Generic clozapine: Outcomes after switching formulations. British Journal of Psychiatry. 2006; 189(AUG.): 184-185. PMid: 16880492. https://doi.org/10.1192/bjp.bp.105.017079

[51] Shankar PR. Medicines use in primary care in developing and transitional countries: fact book summarizing results from studies reported between 1990 and 2006. Bulletin of the World Health Organization. 2009; 87(10): 804. https://doi.org/10.2471/BLT . 09.07041 7

[52] Ofori-Asenso R, Brhlikova P, Pollock AM. Prescribing indicators at primary health care centers within the WHO African region: a systematic analysis (1995-2015). BMC Public Health. 2016; 16(1): 724 PMid: 27545670. https://doi.org/10.1186/s12889-016-3 428-8

[53] Bosu WK, Ofori-Adjei D. An audit of prescribing practices in health care facilities of the Wassa West district of Ghana. West African Journal of Medicine. 2000; 19(4): 298-303 PMid: 11391845.

[54] Odusanya O, Oyediran M. Rational drug use at primary health care centres in Lagos, Nigeria. Nigerian Quarterly Journal of Hospital Medicine. 2000; 10(1): 4-7. Available from: https://www.ajol .info/index.php/nqjhm/article/view/12417

[55] Massele AY, Nsimba SED, Rimoy G. Prescribing habits in churchowned primary health care facilities in dar es salaam and other Tanzanian coast regions. East African Medical Journal. 2011; 78(10): 510-514.

[56] Narendran R, Narendranathan M. Influence of pharmaceutical marketing on prescription practices of physicians. J Indian Med Assoc. 2013; 111: 47-50. PMid: 24000508. Available from: http://pesq uisa.bvsalud.org/portal/resource/es/mdl-24000508

[57] Fugh-Berman A, Ahari S. Following the script: How drug reps make friends and influence doctors. PLoS Medicine. 2000.

[58] Dong L, Yan H, Wang D. Drug prescribing indicators in village health clinics across 10 provinces of Western China. Family Practice. 2011; 28(1): 63-67. PMid: 20876222. https://doi.org/10.1093/fa $\mathrm{mpra} / \mathrm{cmq} 077$

[59] Cole C, James P, Kargbo A. An evaluation of the prescribing patterns for under-five patients at a Tertiary Paediatric Hospital in Sierra Leone. Journal of Basic and Clinical Pharmacy. 2015; 6(4): 109114. PMid: 26692736. https://doi.org/10.4103/0976-0105. 168051 